\title{
THE MYTH OF TEAMWORK IN THE MILITARY
}

\author{
Ştefania BUMBUC*, Maria Dorina PAŞCA ** \\ * "Nicolae Bălcescu" Land Forces Academy, Sibiu, Romania \\ ** University of Medicine and Pharmacy Târgu Mureş, Romania \\ stefanabumbuc@gmail.com, mdpasca@yahoo.com
}

\begin{abstract}
Numerous studies have focused on identifying the relevant conditions and factors that can assure the effectiveness of a team. The purpose of this paper is to present an overview of some positive and negative aspects of the teamwork in the military, using as a starting point the components of a scientific instrument of research. Two of the particular features of the military organization were more detailed analyzed, due to the fact that they turn the potential strengths into weaknesses, and military leaders have to face with them: the formal power of the military leaders and the increased mobility of the military team members.
\end{abstract}

Keywords: team effectiveness, military team

\section{About the effectiveness of a team}

Life experiences and literature show that there are no universal recipes to lead teams to achieve its goals without fail and with minimal costs, but there are known several rules that can guide teams to find their way to performance.

The advantages of the teamwork were strongly highlighted over the time by scholars and practitioners. In respect of the management of organizations in the modern contemporary world, Deborah HarringtonMackin synthesized the following positive aspects of the teamwork [1]:

- highly motivating work environment;

- fast response to technological change;

- simple classifications of jobs;

- flexibility in assigning tasks;

- proactive approach to problems;

- better decisions;

- developing the skills of the staff.

According to the same author, can be noticed in the same time a number of disadvantages of the teamwork within the modern organizations:

- working time may be higher than in the case of independent work;
- work is perceived as disorganized and out of control;

- it can create confusion about individual roles and therefore frustration and lack of motivation can occur;

- it is not approved by conservative managers, who consider that a systematic control exercised from outside the group is necessary;

- it requires the development of people's mentalities, which is a long process;

- if work has been superficially organized, conflicts may arise.

All the aspects listed before were signaled by empirical researches and a lot of issues related to them have been the subjects of extensive studies in the area. Thus, nowadays the researchers focus on the teamwork benefit from a wide range of investigation tools, questionnaires, scales, and other quantitative and qualitative scientific instruments for gathering and processing data.

\section{A complex instrument for measuring the effectiveness of a team \\ One of the foremost contemporary}


researchers of the teamwork field are Richard Hackman, Ruth Wageman and their collaborators from the Harvard University, which developed a theoretical model of a team effectiveness, linking together the leader and the team members' features and actions, as shown in the figure below:

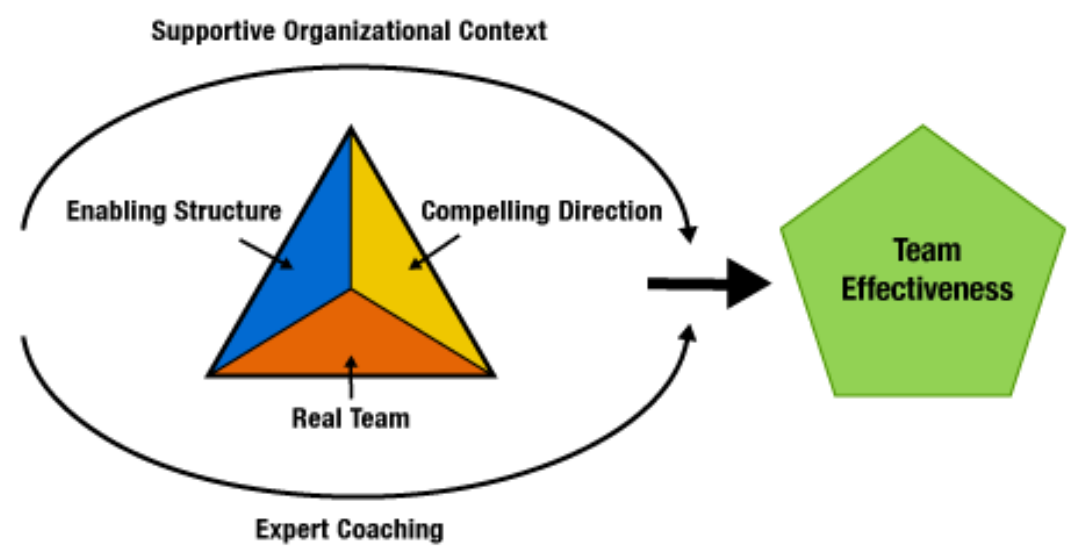

Figure 1: The conditions of team effectiveness [2]:

The conditions for team effectiveness are considered to be the following: "creating a real work team (rather than a set of people who are a team in name only); specifying a compelling direction or purpose for the team; creating an enabling team structure; providing an organizational context that supports teamwork; coaching the team as a team". [3]

Having as a reference these fifth conditions, the group of specialists from Harvard University has succeeded to offer researchers a questionnaire named Team Diagnosis Survey, "an instrument intended to be use both for the diagnosis of the strengths and weaknesses of work teams and for research on team behaviour and performance" [2].

The important managerial measures or changes intended for improving the work teams in an organization should be taken following a scientific conducted study, not only using the intuition or the feelings. On the other hand, these last two resources can be very useful to leaders in addressing daily interactions and solving one-time problems.

\section{Identifying potential barriers and solutions for the team effectiveness}

Literature generically mentions a series of barriers which can decrease team effectiveness, such as: poor planning, poor leadership, poor training, poor attitude, poor communication, poor rapport among team members, and poor recognition and rewards programs. In the present paper we will mention some particular aspects of these potential barriers.

First, we will take into consideration the number of team members, related to their roles in the team. J. R. Hackman considers that the ideal number of members is six, because "the rule of thumb is that no work team should have membership in the double digits" [4]. A lot of researches showed that "the number of performance problems a team encounters increases exponentially as team size increases" [4].

Another problem could be generated by the homogeneity of membership, because usually people works most easily and feels comfortable having around people like them, which belongs to the same age, social or professional categories. Despite the fact that they might very much enjoy the time together, their creativity would be higher if the group contain a diverse mix of members. Different people have real substantive differences in their views about how the work should be structured and executed, and the threats of conflicts within them are so big. But specialist reassures us that the outcomes should be spectacular: "it is task-related conflict, not interpersonal 
harmony that spurs team excellence" [5]. The myth of the clone team named the belief that all team members must have the same skills and attitudes as the team leader. Sometimes team members think that the leader must have the same skills as he does. In fact, homogeneity reduces team efficiency, because some roles are unique. There are also other negative phenomena that occur in the teamwork, consequently leaders struggling to face them by trying different approaches. We can mention the groupthink phenomenon, which could be counteracted by the following measures:

- placing responsibility and authority for certain decisions to a single person who only consults with others or asks for advice;

- selecting a person to act as the devil's lawyer;

- collecting anonymous feedback;

- developing the team creativity

- maintaining critical spirit

Another well known negative issues for the team work are social loafing, and also group inefficiency in routine decisions or taken under time pressure. Making routine decisions in the discussion of a team is counterproductive, because thus the team's energy is consumed in unimportant activities. All that kind of decision should be taken by the leader himself, even if he seems to be too authoritarian.

Given the fact that people behave differently when they belong to different groups, it is not possible to predict the performance of a person in a particular team based on performance achieved in other teams or situations. It is very important for leaders to avoid the preconceptions when assign tasks for the members of a new formed team, and also when they design their expectations.

The conservatism and openness to compromise are also blocking factors for team's effectiveness. The team's effort is the result of a compromise between the objectives, interests and competencies of the members. In order to maintain the team cohesion and structure, a compromise solution is often adopted by the team, even if it is obviously inferior to the value of a solution proposed by a particular team member. Some teams composed by capable individuals have poor performance due to destructive and long debates. Other times, very capable individuals act in their own way, without taking into consideration what their colleagues do, having excessive preoccupation to avoid confrontation, or managing to demolish all solutions by focusing on their drawbacks.

If a team includes a person who is in a higher hierarchical position then more attention is paid to that person and more weight to his views. This is an example for the "seductive" character of the hierarchy. In most of these cases, erroneous decisions and frustration of the other team members occur.

The differences of access to knowledge within the team are a very common situation. If only part of the team members have access to the relevant information or knowledge, the other members will not be able to contribute to the common goal with their full potential. They will feel frustrated and will tend to leave the group activity (if not physically, at least mentally).

Also the individuals' resources are usually different. Some people who have significant resources tend to turn into dominant persons. Among the valuable resources for the teamwork we can mention: communication skills, persuasion, experience in conducting working sessions etc. The team leader must ensure that there are equal chances of participation for all members, encouraging timid or slow persons.

Patrick Lencioni stressed the importance of the mutual trust and stated: "Only when team members no longer feel uncomfortable with the idea of opening up to their colleagues, they start acting without trying to self-protect themselves". [6]

The participative managerial style allows the emergence of competition and internal struggles for power and status, which are often not relevant for the fulfillment of the work tasks. 


\section{Factors that diminish the efficiency of the teamwork in the military}

Following the studies of the teamwork in the military, some peculiarities can be identified as sources of lack of efficiency of the teamwork. We will analyze two of them further on in this paper.

\subsection{The military leader's formal power}

Power, leadership, and formal authority are closely related and defining for the military environment. It is widely accepted that a powerful leader can guide a team to a great performance. Nevertheless, a group of specialists conduct an experiment meant to reveal the relation between the subjective experience of power on leadership dynamics and the team performance. Due to their study, they argued that the psychological effect of power on formal leaders negatively affect the team performance.

The empirical observation of the military organization indicates that as they advance in the rank and in the military hierarchy, formal leaders exert an increased verbal dominance on their subordinates, which reduces the team communication and consequently diminishes team performance. An important aspect must be mentioned: this dynamic rely on the acceptance of other team members to the leader's dominant behavior. L.P. Tost and colleagues consider that "these effects only emerged when the leader holds a formal leadership position" [7].

All inspirational literature and oral stories about great military leaders emphasized their power of character and their charisma as the source of the influence on their followers or their teams. But specialists consider that "there are at least two reasons to suspect that a positive relationship between leader power and team performance may not materialize as often as a functionalist account would predict" [7]. The first argument is that the team dynamic and the outcomes are emergent. It means "they are not pre-existing entities inherent to the team that are simply waiting to be brought forth by the demands of a powerful leader'[7]. Only an intense and complex interaction between team members can produce a team processes, making possible the emergence of ideas that did not prior exist. Research has demonstrated that the power of a leader becomes a psychological feeling, and due to that the powerholders tend to consider people as objects, to be less sympathetic and opened to other people perspectives, to be more likely to apply stereotype instead to really know peoples around, and to be less likely to listen to others.

The combination of these research outcomes implies that "the concentration of power in a formal team leader in the military may not have the straightforward and positive effects on team coordination and collaboration that would be expected in a strictly functionalist account" [7] of the effects of military hierarchy.

As a result of social-psychological researches and empirical observations, we can mention several ways in which the subjective experience of power influences how an individual engages in team leadership in the military organization. First, it can be noticed that the formal power easy leads military leaders to be keener to express their attitudes and opinions in group contexts. Second, individuals who experience "increased feelings of power" come to ignore the experiences, point of views, ideas, and contributions of the subordinates. Formal leaders who are willing to express their attitudes and opinions, and who feel that their perspectives are more valuable than the perspectives of others, are likely to feel entitled to dominate interpersonal interactions with their subordinates. That is the reason why leaders with a high subjective sense of power are likely to feel entitled to monopolize the discussions and verbally dominate the team. Consequently, since open communication is critical to team effectiveness, it can be expected as the higher the leader's feelings of power, the lower the efficiency of the team. 


\subsection{The increased mobility of the military personnel}

The mobility of military personnel is a principle of the human resources policy in the military, in order to enhance the level of professionalization, to avoid the narrow training or the monopolization of knowledge in a particular field, and also in order to avoid the capping and the military boredom in the peace time. The effect of that policy is the frequency of the entry of new members in the military teams. One critical issue that may impede effectiveness of the team is that each member's need to feel accepted by the others.

J.J. Lee and collaborators published recently a study of the impact of new members to the team effectiveness and state that "the need to feel accepted can lead individual members to prioritize fitting in over contributing unique information and adding maximum value to the team" [8]. For example, teams are biased toward repeating previously-mentioned shared information, as opposed to sharing unique information, because repetition helps members appear "cognitively central and thus task competent". More than that, "team members are more likely to share sociallyendorsed information within the team if they believe the information to be useful to the team as compared to information that has not been socially-validated." [8]

Given the high degree of professional specialization, increased risks and danger of military missions, all new members of military teams feel a strong need for group integration, as old members of the teams feel the need to restore the cohesion as quickly as possible. Thus, "individual team members' need for social acceptance may hinder the team's ability to share and integrate information and abilities in order to accomplish their task." [8]

\section{Final considerations}

Here are some aspects generally regarded as positive that can turn into obstacles to the efficiency of military teams.

The military hierarchical organizational structure was considered a successful example even for the civilian organization over the time, and a lot of businesses have taken action patterns from the military. But nowadays, military organization have modified, and in some cases eliminated the rigid approach of the human relationships, harnessing modern types of leadership, while they retained the hierarchical structure.

\section{References}

[1] D. Harrington-Mackin, Cum se formează o echipă de succes, Teora, Bucureşti, 2002, pp. 13-14.

[2] R. Wageman, J. R. Hackman, E.V. Lehman, "Team Diagnostic Survey: Development of an Instrument", The Journal of Applied Behavioral Science, 41(4) /2005, pp.373-398.

[3] http://team-diagnostics.com/wp-content/uploads/2015/01/TDS development techpaper.pdf

[4] J. R. Hackman, R.Wageman, C. M. Fisher, "Leading teams when the time is right: Finding the best moments to act", Organizational Dynamics, 38(3)/2009, pp.192-203.

[5] J.R. Hackman, Leading teams: Setting the stage for great performance, Harvard Business Review Press, Boston, http://hbswk.hbs.edu/archive/2996.html

[6] P. Lencioni, Cinci disfuncții ale muncii în echipă. O fabulă despre lideri, Bucureşti, Curtea veche, 2010.

[7] L.P. Tost, F. Gino, R. P. Larrick. "When Power Makes Others Speechless: The Negative Impact of Leader Power on Team Performance", Academy of Management Journal, no.5, October 2013, pp. 1465-1486.

[8] J.J. Lee, F. Gino, D. M. Cable, B. Staats, "Preparing the Self for Team Entry: How Relational Affirmation Improves Team Performance", Harvard Business School Working Paper, No. 16-111, March 2016, online: http://nrs.harvard.edu/urn3:HUL.InstRepos:26211018 